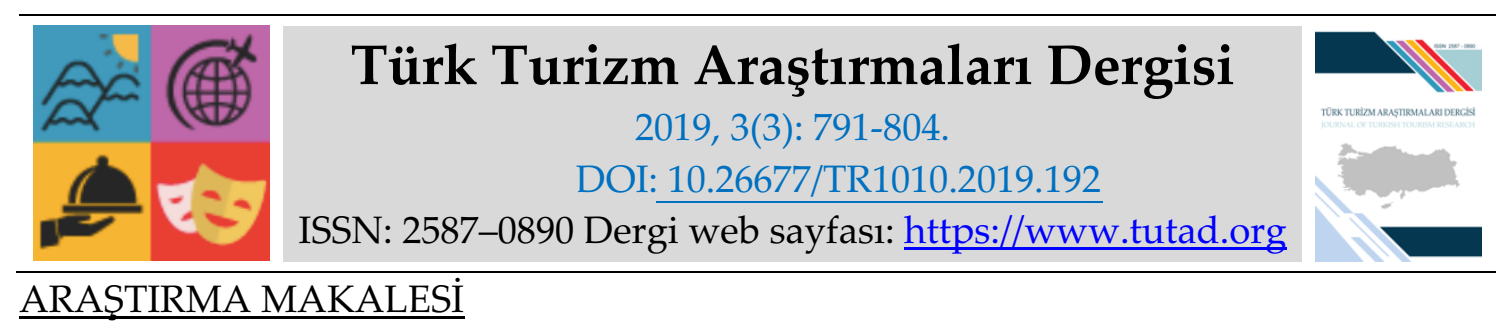

\title{
Akdeniz Ülkelerinde Turizm Sektörünün Ekonomik Etkinliğinin Değerlendirilmesi
}

Dr. Öğr. Üyesi Gonca MANAP DAVRAS, Isparta Uygulamalı Bilimler Üniversitesi, Turizm Fakültesi, Isparta, e-posta: goncadavras@gmail.com ORCID: https://orcid.org/0000-0003-0014-9983

Dr. Öğr. Üyesi Ayşegül BAYKUL, Isparta Uygulamalı Bilimler Üniversitesi, Isparta Meslek Yüksekokulu, e-posta: aysegulbaykul@isparta.edu.tr ORCID: https://orcid.org/0000-0002-7581-9972

Öz

Turizm destinasyonları açısından Akdeniz havzasında yer alan ülkeler dünya turizminde önemli bir yere sahiptir. Dünya turizm hareketliliğinin önemli bir parçası olan bu ülkelerin turizm sektörü bağlamında ülke ekonomisine katkısı birçok çalışmada incelenmiştir. Ancak bu havzada yer alan ülkelerin ekonomik etkinlikleri hakkında çalışmaya rastlanılmamıştır. Bu çalışmanın temel amacı, Akdeniz ülkesi kapsaminda değerlendirilen uluslararası turizm destinasyonlarından verilerine ulaşılabilen ülkelerde turizm sektörünün ekonomik etkinliklerinin değerlendirilmesidir. Çalışmada verileri mevcut olan on dokuz ülkenin turizm sektörünün ekonomik etkinliğine ilişkin dört girdi ve iki çıtı değişkeni kullanılarak etkinlik karşılaştırması yapılmıştır. Çalışmada girdi değişkenleri olarak turistin iç turizm harcamaları, boş zaman harcamaları, iş seyahati harcamaları ve seyahat ve turizm endüstrisindeki yatırımlar, çıtı değişkenleri olarak turizm sektörünün GSYH'ye katkısı ve toplam işgücü içindeki turizm sektörü istihdam oranı kullanılmıştır. Değişkenlerin homojenliğini sağlamak için ülkelerin 2017 yılına ait verileri Travel ve Tourism Economic Impact (WTTC 2018) raporlarından alınmıştır. Ülkelerin ekonomik anlamda etkinliklerinin ölçümünde Veri Zarflama Analizi (VZA) kullanılmıştır. VZA, üretim sınırını etkin bir şekilde tanımlayan, verimlilik ve kapasite kullanımını tahmin etmek için kullanılan parametrik olmayan bir doğrusal programlama yöntemidir. Bulgulara göre ülkelerin turizm sektörünün ekonomik etkinliği açısından ilk beşülke sirasiyla Kıbrıs, Cezayir, Libya, İtalya, Arnavutluk'tur.

Anahtar Kelimeler: Turizm Sektörü, Ekonomik Etkinlik Analizi, Veri Zarflama Analizi (VZA)

Makale Gönderme Tarihi: 11.05.2019

Makale Kabul Tarihi: 08.07.2019

\section{Önerilen Atıf:}

Manap Davras, G. ve Baykul, A. (2019). Akdeniz Ülkelerinde Turizm Sektörünün Ekonomik Etkinliğinin Değerlendirilmesi, Türk Turizm Araştırmaları Dergisi, 3(3): 791-804.

(C) 2019 Türk Turizm Araştırmaları Dergisi. 


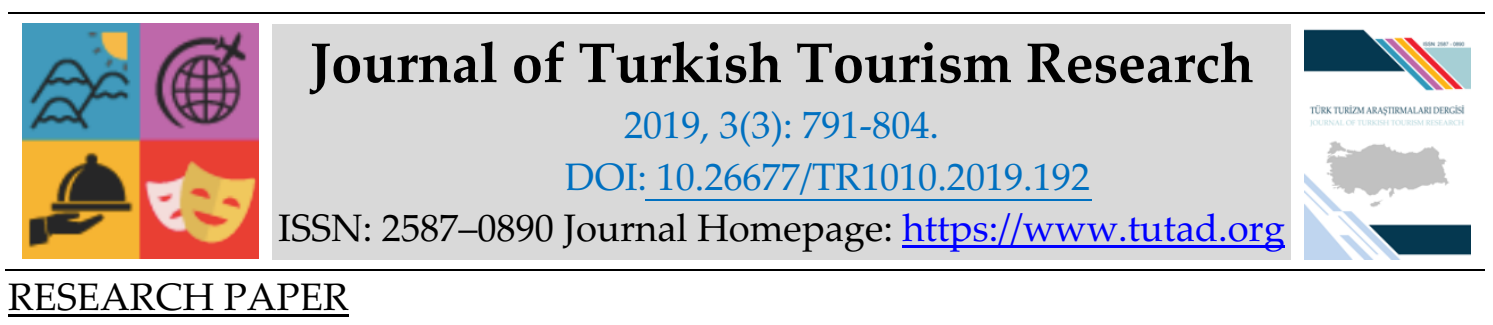

\title{
Evaluation of Economic Efficiency of Tourism Sector in Mediterranean Countries
}

Assistant Prof. Dr. Gonca MANAP DAVRAS, Isparta University of Applied Sciences, Faculty of Tourism, Isparta, e-mail: goncadavras@gmail.com

ORCID: https://orcid.org/0000-0003-0014-9983

Assistant Prof. Dr. Ayşegül BAYKUL, Isparta University of Applied Sciences, Faculty of Tourism, Isparta, e-mail: aysegulbaykul@isparta.edu.tr ORCID: https://orcid.org/0000-0002-7581-9972

\begin{abstract}
Countries in the Mediterranean basin have an important place in world tourism in terms of tourism destinations. The contribution of these countries, which are an important part of world tourism mobility, to the national economy in the context of tourism sector has been examined in many studies. However, there is no study about the economic activities of the countries in this basin. The main purpose of this study is to evaluate the economic activities of the tourism sector in the countries whose data can be accessed from international tourism destinations evaluated within the scope of the Mediterranean country. In the study, efficiency comparison was made by using four input and two output variables related to the economic efficiency of the tourism sector of the nineteen countries whose data are available. In this study, domestic tourism expenditures, leisure time expenditures, business travel expenditures and investments in travel and tourism industry were used as input variables. In order to ensure the homogeneity of the variables, the data of the countries for 2017 are taken from the Travel and Tourism Economic Impact (WTTC 2018) reports. Data Envelopment Analysis (DEA) was used to measure the economic efficiency of countries. DEA is a non-parametric linear programming method used to estimate efficiency and capacity utilization, effectively defining the production limit. According to the findings, the top five countries are Cyprus, Algeria, Libya, Italy and Albania, respectively.
\end{abstract}

Keywords: Tourism Sector, Economic Efficiency Analysis, Data Envelopment Analysis (DEA) Received: 11.05.2019

Accepted: 08.07.2019

Suggested Citation:

Manap Davras, G. and Baykul, A. (2019). Evaluation of Economic Efficiency of Tourism Sector in Mediterranean Countries, Journal of Turkish Tourism Research, 3(3): 791-804.

(C) 2019 Türk Turizm Araştırmaları Dergisi. 


\section{Gíriş}

Tüm dünyada 21. yüzyılın en hızlı ve istikrarlı gelişen ilk üç sektörü arasında sayılan turizm sektörü, sanayi devrimi ile birlikte gelişmeye başlayarak, 1950'den itibaren ülke ekonomilerinin kalkınmasında önemli rol oynamaktadır. Uluslararası turizmin göstermiş olduğu hızlı gelişim, birçok ülkeyi bu endüstriye yöneltmiştir (Usta, 2009: 2). Sürekli gelişim gösteren turizm sektörü, ülkelerin ekonomik gelişiminde etkili ve pratik alternatif fırsatlar sunmaktadır. Özellikle bazı az gelişmiş veya gelişmekte olan ülkelerde ekonominin yapı taşını oluşturan turizm, seyahatten konaklamaya, ulaşımdan yeme içmeye kadar geniş bir yelpazeye sahiptir. Ayrıca ülkenin kendi kaynaklarını kullanarak döviz gelirini ucuz ve zahmetsiz sağlama imkânı veren, etki alanı geniş olan turizm sektörünün, turist çeken ülkeler için olduğu kadar turist gönderen ülkeler içinde önemli ekonomik etkileri bulunmaktadır.

Turizm, ülkelerin ekonomik kalkınmalarını gerçekleştirmek için gerekli döviz girdisini sağlama, gelir yaratma, bölgelerarası gelişimi dengeleme, özellikle kırsal alanlarda istihdam olanaklarını arttırma özelliği ile öncü sektör olmuştur. Ayrıca, vergi gelirleri oluşturma, yatırım imkânları sağlayarak bölge ve ülke kalkınmasına katkı sağlama özelliklerine sahiptir (Bahar ve Kozak, 2013: 12-13; Çımat ve Bahar, 2003: 2). Bacasız sanayi olarak adlandırılan bu sektörün ülke ekonomisine en önemli katkılarından biri de şüphesiz ödemeler dengesi üzerindeki olumlu etkisidir (Thano, 2015: 530; Zaei ve Zaei, 2013; Çelik vd., 2013). Yabancı turistlerin ülkeye gelerek harcama yapmaları, diğer yandan iç turizm faaliyeti kapsamında vatandaşların ülke içerisinde yapmış olduğu harcamaları ödeme dengesini olumlu yönde etkilemektedir (Türkcan, 2018: 161)

Dünya'da uluslararası turizm hareketliliği düzenli artışını sürdürerek 2017 yılında turist sayısı 1.341 milyon kişiye ulaşmıştır. Grafik 1.'de 1995-2017 yılları arasındaki turizm hareketliğine bakıldığında 1995 yılından 2017 yılına kadar turizm hareketliğinde \%156 oranında bir artış olduğu görülmektedir.

Grafik1. 1995-2017 Uluslararası Turizm Hareketliliği

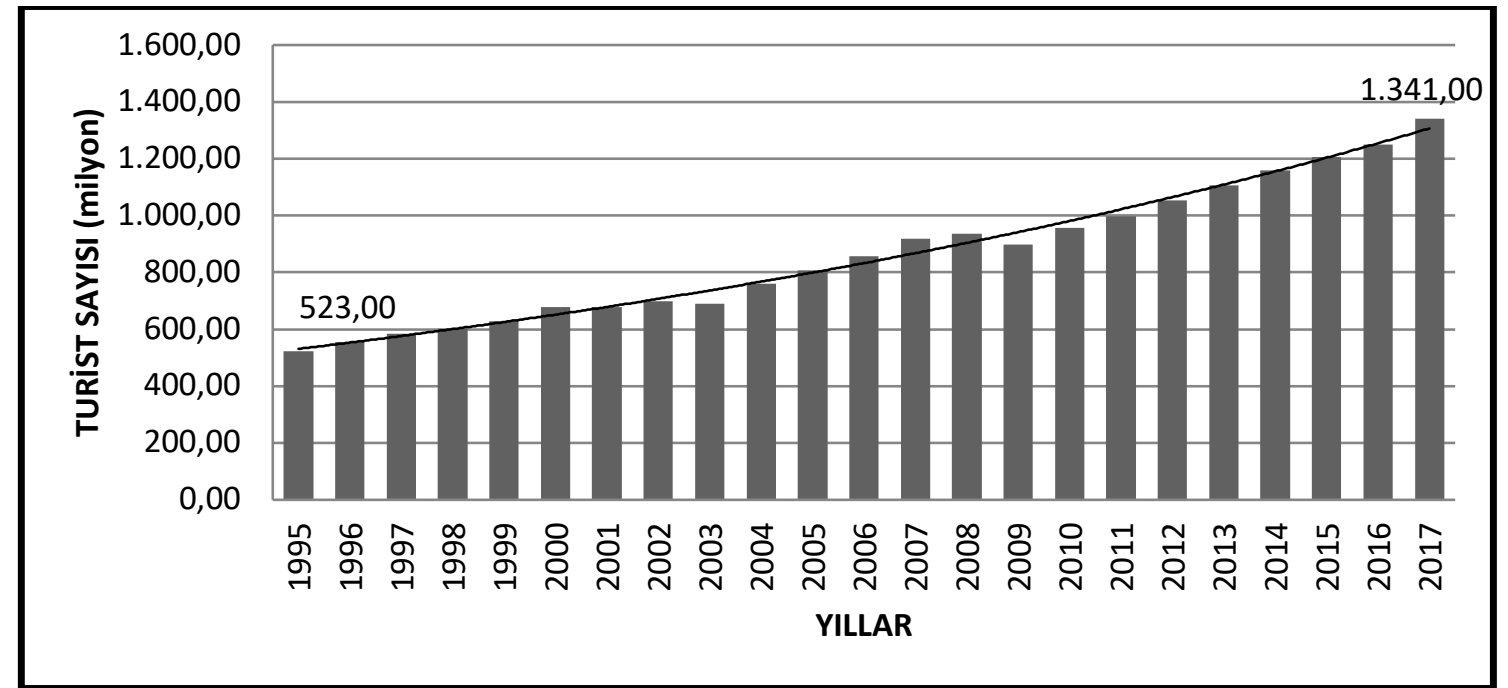

Kaynak: World Tourism Organization, 2018.

Birleşmiş Milletler Dünya Turizm Örgütü (UNWTO) tarafından yayımlanan World Tourism Highlights 2018 raporuna göre, tüm dünyada 2017 yılı turizm hareketliliği kapsamında ziyaretçilerin \%51'i Avrupa'ya (672 milyon), \%24'ü Asya Pasifik ülkelerine (323 milyon), \%16'sı Amerika'ya (211 milyon), \%5' i Afrika'ya (63 milyon) ve \%4'ü Orta Doğu'ya (58 milyon) seyahat etmiştir. Turistlerin tercih ettiği ilk beş ülke Fransa ( 86,9 milyon), İspanya ( 81,8 milyon), ABD (76,9 milyon), Çin (60,7 milyon) ve İtalya (58,3 milyon) olarak sıralanmaktadır. 
Dünya genelindeki destinasyonlar tarafından elde edilen turizm gelirleri Grafik 2'de sunulmaktadır. 1995'ten 2017 yılına kadar dünya turizm gelirleri \%215 oranında artarak 1.525 milyar dolara ulaşmıştır (UNWTO, 2018)

Grafik 2. 1995-2017 Uluslararası Turizm Gelirleri (milyar \$)

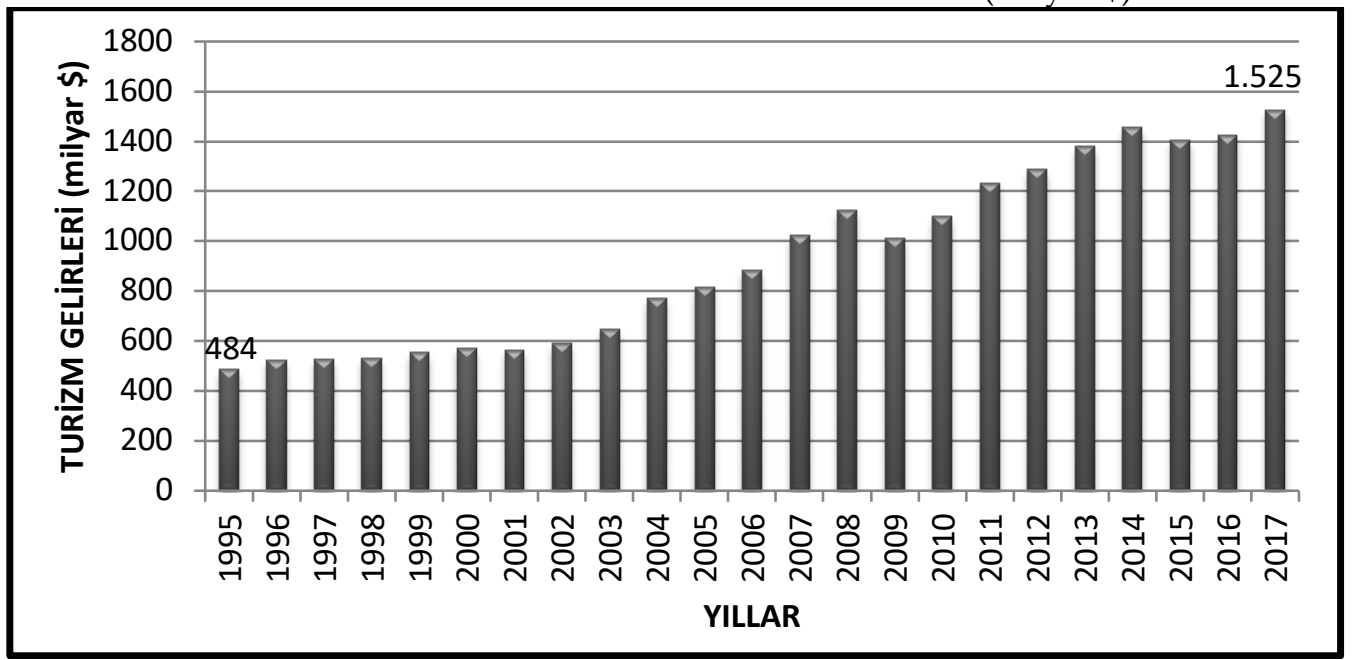

Kaynak: World Tourism Organization, 2018

$\mathrm{Bu}$ hareketlilik sonucu en fazla turizm geliri sağlayan ülkelere bakıldığında, ilk beş ülke ABD (210,7 milyar \$), İspanya (68 milyar \$), Fransa (60,7 milyar \$), Tayland (57,5 milyar \$), İngiltere (51,2 milyar \$) olarak sıralanmaktadır (UNWTO, 2018). Birleşmiş Milletler Dünya Turizm Örgütü'nün 2017 verilerine göre, Türkiye en çok tercih edilen ülkeler arasında 8. sırada iken turizm gelirlerinde ilk 10 ülke listesinde yer alamamıştır.

Sektörün ekonomik olarak katkıları incelendiğinde, dünyanın en büyük ekonomik sektörlerinden birinin turizm sektörü olduğunu söylemek çokta yanlış olmayacaktır. Sektör, 2017 yılında küresel GSYH'nın \%10,4'ünü ve 313 milyon iş yaratarak toplam istihdamın \%9,9'unu oluşturmuştur. Dünya Seyahat ve Turizm Konseyi (WTTC) tarafından hazırlanan Seyahat/Turizmin Ekonomik Etkileri raporunda, turizm sektörünün ekonomik katkı kriterleri ve boyutlarına yer vermiştir. Şekil 1'de yer alan bu kriter ve boyutlar verilmektedir. (WTTC, 2018).

DOĞRUDAN EKONOMIK KATKI KALEMLER

Konaklama, Ulaştırma, Eğlence, Çekiciler ENDÜSTRILER

Konaklama,Yeme-içme, Perakende, Ulastırma, Kültürel-sportif ve Rekreatif Hizmetler

\section{HARCAMA} KAYNAKLARI

Yerleşiklerin Seyahat ve Turizm Harcamaları, İşletmelerin Seyahat ve Turizm Harcamaları, Ziyaretçilerin İhracat Etkisi, Hükümet Seyahat Ve Turizm Harcamaları

Kaynak: WTTC, 2018: 2

\section{Şekil 1.Turizm Sektörünün Ekonomik Katkı Kriterleri ve Boyutları}


Sektörün ekonomik açıdan toplam katkısı, Gayri Safi Yurt içi Hasıla (GSYH) içindeki payı ve istihdam yaratma düzeyi gibi iki temel gösterge ile ifade edilmektedir. GSYH, ülke sınırları içinde bir yıl içinde üretilen tüm nihai mal ve hizmetlerin toplam parasal değerini gösterir. Ülkenin ekonomik anlamda gelişmişliğini gösteren en önemli makro göstergelerden biridir. GSYH'sındaki artışlar ülkenin ekonomik büyümesini ifade ederken turizm sektörünün GSYH içindeki payı ise ülkenin büyümesine olan katkısını ifade etmektedir.

Ekonomik açıdan bir diğer gösterge de istihdam yaratma düzeyidir. Hizmet sektörü içinde yer alan emek yoğun üretim tekniğine dayanan sektör, istihdam olanaklarını da yaratabilmesi açısından önemli bir alan oluşturmaktadır (Çımat ve Bahar, 2003: 14). Turizm işletmeleri bünyesinde yaratılan istihdam olanaklarının yanı sıra turizm sektörünün ilişkide bulunduğu diğer pek çok sektörde yarattı̆̆ dolaylı istihdam yaratma düzeyi oldukça yüksektir. Doğrudan ve dolaylı istihdamla sağlanan gelir harcandıkça turizmin çarpan etkisiyle ekonomide yaratılan istihdam etkisi de artmaktadır (Page ve Connell, 2014: 283; Ünlüönen ve Şahin, 2011: 4).

Turizmin uluslararası gelir ve istihdam kaynağı olarak ekonomik önemi ve küresel turizm piyasasındaki artan rekabet nedeniyle, ülkelerin turizm faaliyetlerinden yararlanarak ekonomilerini daha iyi konuma getirebilme çabalarında uygun büyüme stratejileri geliştirebilmeleri ve uygulayabilmeleri önemli bir konudur. Hedeflenen düzeye erişmek için uygulanacak politikalar da ve stratejiler de ülkenin rakipleri karşısında mevcut durumu ortaya konmalıdır. Aynı derecede önemli olan bir diğer konu da mevcut turizm faaliyetlerinin performansının değerlendirme ihtiyacıdır (Pestana vd., 2011). Performansın en önemli unsuru olan etkinlik sektör odaklı ifade edilirse; bir sektörün çıtılarını oluşturmak için kullandığı girdileri ne düzeyde etkili kullanabildiğini gösteren ölçüttür (Fare vd., 2007). Etkinlik, fiili (gerçekleşen) performans, önceden saptanan standart (olması gereken) performans ile karşılaştırıldığında gerçekleşen performansın standart performansa ne ölçüde yaklaşıp yaklaşmadığını gösterir (Yükçü ve Atağan, 2009:3).

Uzun vadede, belli bir bölgedeki turist destinasyonlarının yaşam döngüsü, büyük ölçüde sektörde hedeflenen seviyeye ulaşmak için girdileri etkili bir şekilde birleştirme ve yönetme yeteneğine bağlıdır. Bu nedenle, ülkenin sektörden beklediği hedefler ve girdileri iyi analiz edilerek doğru adımlar atılmalıdır. Turist destinasyonlarının performansı değerlendirilecek ise etkin kaynak kullanımının ölçümü ile değerlendirilebilir (Cracolici vd., 2008: 326).

$\mathrm{Bu}$ çalışmada, Akdeniz havzasında yer alan ülkelerdeki turizm sektörünün ekonomik etkinliklerinin değerlendirilmesi amaçlanmaktadır. Turizm sektöründe etkinliğin mikro düzeyde ölçülmesi önemli bir araştırma konusu olmasına rağmen, makro düzeyde çok az araştırma bulunmaktadır. Bu nedenle bu çalışma ile literatüre önemli katkı sağlanmaktadır. Ülkelerin turizm sektörüne ilişkin etkinlik karşılaştırmalarında kullanılacak veri seti sorununa, uluslararası güvenilirliği ve geçerliliği olan Dünya Seyahat ve Turizm Konseyinin (WTTC) 2018 yılında hazırlamış olduğu Seyahat ve Turizmin Ekonomiye Etkisi raporlarından faydalanarak çözüm bulunmuştur.

\section{LITERATÜR}

Turizm sektöründe etkinlik, diğer sektörlerde olduğu gibi girdi miktarını çıktılarla ilişkilendirerek kaynakların ne düzeyde verimli kullanıldığına açılama getirmeye çalışır. Örneğin destinasyonun etkinliği, turistlerin beklentilerini karşılayacak nitelikte hizmetleri sunmak için gerekli girdileri uygun şekilde kullanma becerisidir (Fuchs, 2004). 
Veri zarflama analizi (VZA) ve türevleri kullanılarak, turizm alanında etkinlik değerlendirmeye yönelik çeşitli çalışmalar yapılmıştır. Ancak bu çalışmalar daha çok mikro düzeyde otellerin, seyahat acentelerinin, yerel turizm destinasyonlarının etkinliklerini değerlendirme amacı taşımaktadır. Uluslararası destinasyonlar düzeyinde sınırlı çalışma bulunmaktadır.

Hadad vd., (2012) nin yaptığı çalışmada 34 gelişmiş, 71'i gelişmekte olan toplam 105 ülkenin turizm sektörü etkinliği veri zarflama analizi ve süper etkinlik metodu kullanarak değerlendirmişlerdir. Çıktı değişkeni olarak turist sayısı ve turist başına gelir, girdi değişkeni olarak da işgücü, otel oda sayısı, kültürel ve doğal kaynaklar kullanmıştır. Çalışma sonucunda gelişmiş ülkelerde Lüksemburg, Fransa, İrlanda ve Singapur; gelişmekte olan ülkelerde Ukrayna, Bosna, Bruney, Bahreyn, Porto Riko, Macaristan ve Hırvatistan etkin bulunmuştur.

Assaf ve Barros (2013), 2006-2008 yılları verilerine dayanarak 37 ülkedeki 519 oteli analiz etmişlerdir. Satış sayısı, tam zamanlı çalışan personel sayısı ve diğer işletme maliyetleri olmak üzere 3 girdi, operasyonel gelir, yıllık doluluk oranı ve pazar payı olmak üzere 3 çıktı değişkeni kullanmıştır. Çalışma sonucunda otel endüstrisinde en verimli ülkeler İsviçre, İspanya, Birleşik Krallık (İngiltere), Birleşik Arap Emirlikleri (BAE) olurken en az verimli ülkeler Hırvatistan, Slovakya ve Kenya olarak belirlenmiştir.

Kosmaczewska (2014), 2007-2009 yılları verilerine göre 27 Avrupa Birliği (AB) ülkesini CCR, BCC ve NIRS (ölçeğe göre azalan getiri) modelleriyle analiz etmiştir. Girdi değişkeni olarak turizm konaklama tesislerine gelenler; çıtı değişkeni olarak da otel işletmeleri sayısı ve kişi başına düşen GSYH kullanılmıştır. Sonuç olarak, zengin ve fakir ülkelerin verimlilikleri arasında anlamlı bir fark olamadığını bulmuştur.

Atan ve Arslantürk (2015), 2006-2010 yılları için CCR ve BCC modelleri ile dünya çapındaki 91 ülkenin verimliliklerini analiz etmişlerdir. Girdi değişkeni olarak gelen yolcu sayısı, hareketlilik sayısı, turizm harcamaları, ulaşım harcamaları ve seyahat ihtiyaçları için turizm harcamalarını kullanmıştır. Çıktı değişkeni olarak turizm gelirleri, yolcu ulaşımı için turizm gelirleri ve seyahat için turizm gelirleri kullanılmıştır. Çalışma sonucunda, CCR modele göre 65 ülke, BCC modeline göre 67 ülke etkin bulunmuştur. Türkiye'nin her iki modelde de tüm dönemlerde etkin olduğu saptanmıştır.

Soysal-Kurt (2017)'un VZA yöntemini kullanarak 29 Avrupa ülkesinin turizm etkinliğini karşılaştırdığı çalışmada 16 ülkenin turizm sektörü etkin bulunurken, 13 ülkenin turizm sektörü etkinliği sınır değerinin altında bulunmuştur. Çalışmada çalışan sayısı, turizm için yapılan altyapı harcamaları ve yatak kapasitesi olmak üzere 3 girdi, uluslararası turist sayısı, turizm geliri ve geceleme sayısı olmak üzere 3 çıkı değişkeni kullanılmıştır.

Göral (2018), 19 ülkenin turizm sektörüne ilişkin dört girdi ve iki çıtı değişkeni kullanılarak etkinliği araştırılmıştır. Girdi değişkenleri olarak turizm sektöründe çalışanların sayısı, turizm sektörü altyapısı, doğal kaynaklar ve kültürel kaynaklar, çıktı değişkenleri olarak turist sayısı ve turist başına ortalama gelir kullanılmıştır. Girdi ve çıktı değişkenlerinin homojenliğini sağlamak üzere uluslararası güvenilir raporlardan elde edilen verilerden yararlanılmıştır. Ülkelerin etkinliğini ölçmek ve sıralamak üzere Veri Zarflama Analizi ve TOPSIS Temelli Etkinlik Sıralama (ESM-VT) yöntemi kullanılmıştır. Sonuçlara göre Hong Kong, ABD ve Hindistan turizm sektörü etkinliği açısından ilk üç sırada yer alırken, Meksika (19) ve Rusya (18) son sıralarda yer almıştır. Göral ve Tengilimoğlu (2018), Türk Dünyasının önde gelen uluslararası turizm destinasyonlarının etkinliklerini karşılaştırmıştır. Çalışmada altı turizm sektörüne ilişkin dört girdi ve iki çıktı değişkeni kullanılarak etkinlik karşılaştırması yapılmıştır. Turizm sektöründe çalışanların sayısı, turizm sektörü altyapısı, doğal kaynaklar ve kültürel kaynaklar girdi, turist sayısı ve turist başına ortalama gelir çıktı olarak kullanılmıştır. Ülkelerin etkinliğini ölçmek ve sıralamak üzere Veri Zarflama Analizi ve TOPSIS Temelli Etkinlik Sıralama (ESM-VT) yöntemi 
kullanılmıştır. Bulgulara göre ülkelerin turizm sektörü etkinliği sırasıyla Türkiye, Azerbaycan, Moğolistan, Kırgızistan, Kazakistan, Tacikistan şeklindedir.

Gürsoy ve Göral (2019) Dünya Ekonomik Forumu (WEF) Seyahat ve Turizm Rekabet Raporu 2017 verilerinden yararlanarak 129 ülkenin turizm sektörünün etkinliği hesaplanmış ve bir verimlilik endeksi oluşturulmuştur. Sektör etkinliğini hesaplamak için Süper verimlilik yöntemi kullanılmıştır. Çalışmada ülkelerin turizm sektörünün etkinliğini ölçmek için dört girdi ve iki çıktı değişkeni kullanmıştır. Girdi değişkenleri işgücü, oda sayısı, doğal kaynaklar ve kültürel kaynaklar, çıktı değişkenleri uluslararası turistlerin sayısı ve turist başına ortalama gelir olarak belirlenmiştir. Araştırmanın bulgularına göre, turizm sektörü etkinliği açısından Bangladeş, Lüksemburg ve Çin ilk üçe girerken, Yemen, Lesoto ve Malavi son sırada yer almaktadır.

Konu hakkında yapılan çalışmalar incelendiğinde, ortak bir sonuca varmanın mümkün olmadığı görülmektedir. Çünkü VZA seçilen değişkenlere/karar birimlerine/modele göre farklı sonuçlar vermektedir. Ancak çalı̧̧mada ekonomik etkinliği ölçmek için kullanılan değişkenler literatür ile uyumludur. Özellikle Akdeniz ülkelerini ele alan bir çalışmaya rastlanılmamıştır.

\section{METODOLOJİ}

VZA, üretim sınırını etkin bir şekilde tanımlayan, verimlilik ve kapasite kullanımını tahmin etmek için kullanılan parametrik olmayan bir doğrusal programlama yöntemidir (Charnes vd., 1978). Bir VZA uygulamasındaki gözlem birimleri, karar verme birimi (KVB) olarak adlandırılır. Bu yöntemde, en az girdi bileşimini kullanarak en çok çıktı bileşimini üreten "en iyi" karar verme birimi (KVB) belirlenir. Belirlenen en iyi KVB'ye göre etkinlik sınırı oluşturulur. Etkin olmayan $\mathrm{KVB}^{\prime}$ lerin etkinlik skorlarl; etkin olan $\mathrm{KVB}^{\prime}$ ler tarafından oluşturulan etkin üretim sınırına (referans kümesi) olan uzaklıklarına göre hesaplanmaktadır. Bu yöntem, çoklu girdi ve çoklu çıtıdan oluşan karar verme birimlerinin değerlendirilmesinde kendine özgü avantajlara sahiptir.

VZA modellerinden yararlanılarak yapılacak analiz, kullanım alanlarına ve varsayımlara göre belirlenmektedir. Özellikle girdiye ve çıktıya yönelik model seçiminde karar verilirken eğer girdi üzerinde denetim mevcutsa girdiye yönelik, çıktı üzerinde denetim mevcutsa çıktıya yönelik modeller tercih edilmektedir. Modelde seçtiğimiz veriler doğrultusunda çıktı odaklı model kullanilacaktır. (Charnes ve Cooper, 1985; Banker ve Morey 1986)

Sabit getiri varsayımına göre modelin (CCR-O) hedefi girdilerin sabit tutularak çıktının ne kadar arttırılabileceğidir. Ölçeğe göre sabit getiri varsayımı atında girdi/çıktı oranı minimize edilmek suretiyle etkinlik hesaplanmaktadır. $m$ adet girdisi ve $s$ adet çıktısı olan $n$ adet karar verme birimi için maksimize edilecek çıktıya yönelik CCR kesirli programlama modelinin matematiksel ifadesi aşağıdadır.

ur: o. KVB tarafından r. çıktıya verilen ağırlık değeri

vi: o. KVB tarafından i. girdiye verilen ağırlık değeri

xio: o. KVB'nin kullandığı i. girdi miktarı

yro: o. KVB'nin elde ettiği r. çıktı miktarı

$x_{\mathrm{ij}:}$ j. KVB'nin kullandığı i. girdi miktarı

$y_{r i}: j$ j. KVB'nin elde ettiği r. çıktı miktarı

$v_{o}:$ " $\mathrm{o}$ " KVB'ye ait serbest işaretli değişken

$\varepsilon: 10^{-6}$ gibi küçük bir say1 
Değişken getiri varsayımına göre model (BCC-O) mevcut girdilerle üretilebilecek maksimum çıktı miktarını belirlemektedir. CCR modelleri ile KVB'lerin, teknik etkinlik skorları elde edilirken, BCC modelleriyle saf teknik etkinlik değerleri elde edilmektedir (Lorcu 2008: 70).

Çizelge 1. Çıktı Odaklı CCR ve BCC Modelinin Formülasyonu

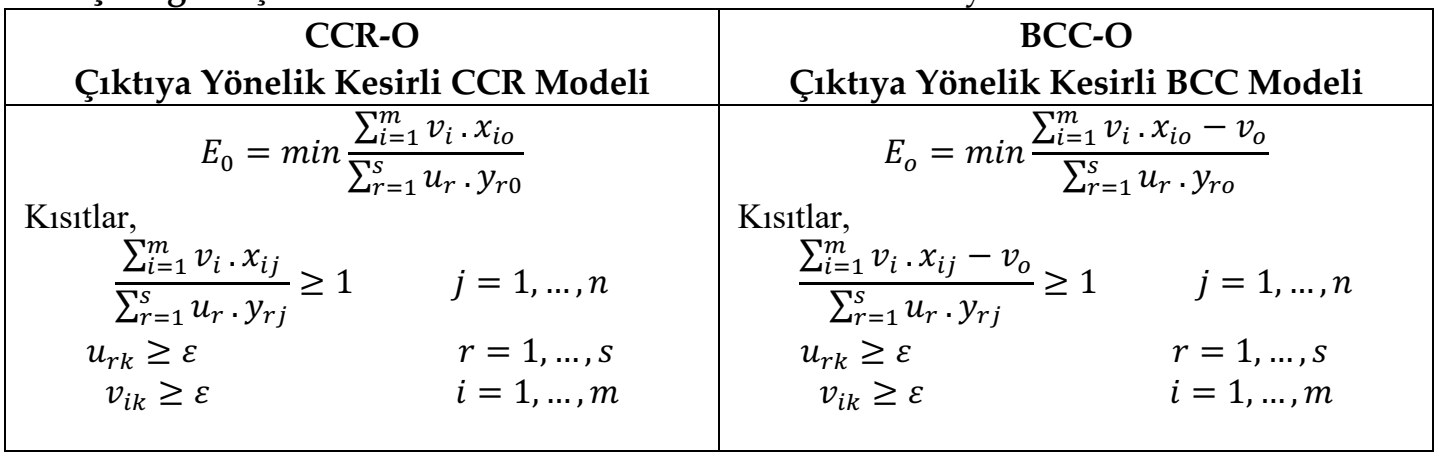

Temel VZA modelleri ile sıralama olanağı bulunmayan durumlarda süper aylak tabanlı model ile çözülerek sıralama yapılabilmektedir. Bu nedenle çalışmanın bir parçası olarak sıralama yapmaya imkân veren SupSBM-O modeli ile sıralama yapılacaktır.

\section{BULGULAR}

Akdeniz Havzası ülkeleri farklı dil, din ırk özellikleri gösterseler de turizm açısından birbirine yakın turistik ürün (deniz, kum, güneş, arkeolojik eserler vb.) sunmaktadır. (Patsouratis vd., 2005:1866). Bu nedenle Türkiye'nin turizm sektöründeki en güçlü rakipleri Akdeniz ülkeleridir (Kozak ve Rimmington 1999; Kozak 2004; Bahar ve Kozak 2005). Çalışma kapsamında, Akdeniz ülkelerinin etkinliklerinin ortaya konulabilmesi için ülkenin en yakın rakibi olan Akdeniz çanağında Arnavutluk, Bosna-Hersek, Cezayir, Fas, Fransa, Hırvatistan, İspanya, İsrail, İtalya, Karadağ, Kıbrıs (Kuzey Kıbrıs Türk Cumhuriyeti ve Güney Kıbrıs Rum Yönetimi), Libya, Lübnan, Malta, Misır, Monako, Slovenya, Suriye, Tunus, Türkiye ve Yunanistan olmak üzere 21 ülke dikkate alınmıştır. Monako ve Malta ülkelerinin tüm verine ulaşılamadığı için çalışmaya dâhil edilmemiştir.

VZA yöntemi ile ülkelerin etkinliğini hesaplamak için beş girdi iki çıktı değişkeni kullanılmıştır. Çalışmada kullanılan girdi değişkenleri ile çıktı değişkenleri doğrudan ve dolaylı olarak ilişkilidir.

Çizelge 2. Çalışmada kullanılan girdi ve çıktı değişkenleri

\begin{tabular}{|c|c|}
\hline GİRDİ DEĞİŞKENLERİ & AÇIKLAMA \\
\hline Ziyaretçi harcamaları (VE) & Toplam ihracat içinde ziyaretçi harcamaları \% \\
\hline Yerleşiklerin harcaması (DS) & GSYH içindeki yerleşik harcamaları \% \\
\hline Eğlence harcaması (LS) & $\begin{array}{l}\text { Ülke GSYH'ne Seyahat ve Turizm GSYH' sının doğrudan } \\
\text { katkıları içindeki eğlence ve turizm harcamaları \% }\end{array}$ \\
\hline İş Seyahati Harcaması (BS) & $\begin{array}{l}\text { Ülke GSYH'ne Seyahat ve Turizm GSYH' sının doğrudan } \\
\text { katkıları içindeki iş seyahati ve turizm harcamaları \% }\end{array}$ \\
\hline Turizm sektörü yatırımları (TI) & $\begin{array}{l}\text { Toplam yatırımlar içinde turizm sektörüne yapılan } \\
\text { yatırım \% }\end{array}$ \\
\hline ÇIKTI DEĞİŞKENLERİ & AÇIKLAMA \\
\hline GSYH Katkısı (GDP) & $\begin{array}{l}2017 \text { yılında turizm sektörünün GSYH'ye toplam katkısı } \\
\text { (doğrudan, dolaylı ve uyarılmış) }\end{array}$ \\
\hline İstihdam Katkısı (EMP) & $\begin{array}{l}2017 \text { yılında turizm sektörünün istihdama toplam katkısı } \\
\text { (doğrudan, dolaylı ve uyarılmış) }\end{array}$ \\
\hline
\end{tabular}


Çalışma kapsamındaki 19 Akdeniz ülkesine ait 2017 yılı verileri ile elde edilen teknik (CCR), saf teknik (BCC), ölçek etkinliği değerleri ile ölçeğe göre getirileri Tablo 1'de verilmiştir.

Tablo 1. Model Sonuçları

\begin{tabular}{|c|c|c|c|c|c|c|c|}
\hline ÜLKELER & T-CCR-O & $\%$ OTE $^{1}$ & T-BCC-O & $\%$ PTIE $^{2}$ & ÖLÇEK & SEI $\%{ }^{3}$ & $\begin{array}{c}\text { ÖLÇEĞE } \\
\text { GÖRE } \\
\text { GETIRİ }\end{array}$ \\
\hline ARNAVUTLUK & $100 \%$ & 0 & $100 \%$ & 0 & $100 \%$ & 0 & Sabit \\
\hline CEZAYİR & $100 \%$ & 0 & $100 \%$ & 0 & $100 \%$ & 0 & Sabit \\
\hline $\begin{array}{l}\text { BOSNA } \\
\text { HERSEK }\end{array}$ & $100 \%$ & 0 & $100 \%$ & 0 & $100 \%$ & 0 & Sabit \\
\hline KIBRIS & $100 \%$ & 0 & $100 \%$ & 0 & $100 \%$ & 0 & Sabit \\
\hline YUNANISTAN & $100 \%$ & 0 & $100 \%$ & 0 & $100 \%$ & 0 & Sabit \\
\hline İSRAİL & $100 \%$ & 0 & $100 \%$ & 0 & $100 \%$ & 0 & Sabit \\
\hline ITALYA & $100 \%$ & 0 & $100 \%$ & 0 & $100 \%$ & 0 & Sabit \\
\hline SLOVENYA & $100 \%$ & 0 & $100 \%$ & 0 & $100 \%$ & 0 & Sabit \\
\hline HIRVATISTAN & $100 \%$ & 0 & $100 \%$ & 0 & $100 \%$ & 0 & Sabit \\
\hline SURIYYE & $100 \%$ & 0 & $100 \%$ & 0 & $100 \%$ & 0 & Sabit \\
\hline LİBYA & $100 \%$ & 0 & $100 \%$ & 0 & $100 \%$ & 0 & Sabit \\
\hline LÜBNAN & $99 \%$ & 1 & $100 \%$ & 0 & $99 \%$ & 1 & Artan \\
\hline İSPANYA & $95 \%$ & 5 & $98 \%$ & 2 & $96 \%$ & 4 & Artan \\
\hline TÜRKİYE & $93 \%$ & 7 & $93 \%$ & 7 & $100 \%$ & 0 & Sabit \\
\hline FRANSA & $86 \%$ & 14 & $86 \%$ & 14 & $100 \%$ & 0 & Sabit \\
\hline TUNUS & $85 \%$ & 15 & $99 \%$ & 1 & $86 \%$ & 14 & Artan \\
\hline FAS & $76 \%$ & 24 & $88 \%$ & 12 & $87 \%$ & 13 & Artan \\
\hline KARADAĞ & $68 \%$ & 32 & $93 \%$ & 7 & $72 \%$ & 28 & Artan \\
\hline MISIR & $60 \%$ & 40 & $62 \%$ & 38 & $97 \%$ & 3 & Azalan \\
\hline
\end{tabular}

CCR-O modeline göre toplam 11 ülke teknik etkin olarak bulunmuştur. Bu modele göre 3 ülke \%90-99 aralığında, 2 ülke \%80-89 aralığında, 1 ülke \%70-79 aralığında, 2 ülke \%60-69 aralığındadır. Teknik etkinlik değeri \%50'nin altında olan ülke bulunmamaktadır. Mısır en düşük teknik etkinlik değerine sahip ülkedir. Teknik etkinlik (TE), girdilerin verimliliği ile ilgilidir. (Sathye, 2001) Bir KVB'nin teknik etkinliği üretim imkânları eğrisi sınırını gösterildiği gibi, çıktılarını elde etmek için girdileri gerçekten ne kadar iyi kullandığının karşılaştırmalı bir ölçüsüdür (Barros ve Mascarenhas, 2005). Teknik etkinsizlik oranları \%1-40 arasında değişmektedir. Seçilen değişkenlere göre etkinsizliğin nedenini bulmak için saf teknik etkinlik (STE) değerleri (BBC-O modeli) ve ölçek etkinlik değerleri hesaplanmıştır. TE ölçeğe göre sabit getiri varsayımı altında hesaplanırken, STE değeri ölçeğe göre değişken getiri varsayımı altında hesaplanir.

${ }^{1}$ OTIE $\%=$ Overalltechnicalinefficiency $=(1-\mathrm{OTE}) \times 100$

${ }^{2} \mathrm{PTIE} \%=$ Puretechnicalinefficiency $=(1-\mathrm{PTE}) \times 100$

${ }^{3} \mathrm{SIE}(\%)=$ Scaleinefficiency $=(1-\mathrm{SE}) \times 100$ 
BCC-O modeline göre ise 12 ülke saf teknik etkin (STE) çımıştır. 4 ülke \%90-99 aralığında, 2 ülke \%80-89 aralığında, 1 ülke \%60-69 aralığındadır. Saf teknik etkinlik değeri \%50'nin altında olan ülke bulunmamaktadır. Mısır en düşük saf teknik etkinlik değerine sahip ülkedir.

Sonuçlar ölçek etkinliği bakımından irdelendiğinde; 13 ülke ölçek etkin, 6 ülke ölçek etkin değildir. Bu ülkelerden ölçeğe göre; 13'ü sabit, 5'i artan, 1 ülke ise azalan getiriye sahiptir. Hem teknik hem de saf teknik etkinlik değerlerine göre etkin olmayan Türkiye ve Fransa ölçek etkin olarak bulunmuştur. Ölçek etkinliği (SE), yönetimin en uygun kaynak boyutunu seçmesini, beklenen üretim seviyesine ulaşacak üretim ölçeğini seçmesini sağlar. Bir KVB'nin uygunsuz büyüklüğü bazen teknik yetersizliğe neden olabilir. Ölçek etkinsizliği ya artan ya da azalan özellik gösterir. Azalan özellik gösteriyorsa uygun ölçekte faaliyet göstermediği şeklinde yorumlanır. (Mısır) Ölçeğe göre artan getiri_özelliğini gösteren ve etkinlik sınırından uzak olan bir KVB, aynı girdi ile fazla çıktı üretecekken potansiyelini kullanamayarak az çıktı üretmiştir. Potansiyel kullanımı burada tamamen diş etkilerden (coğrafi, iklim, konum vs.) kaynaklanmaktadır. Bu kapasite kullanım yetersizliği olarak adlandırılmaktadır. (Lübnan, İspanya, Tunus, Fas, Karadağ)

VZA'da etkinlik değeri hesaplanacak olan KVB'nin lehine olacak şekilde, o KVB'nin diğer KVB'lere göre göreli olarak, en çok ürettiği çıktılara ve en az kullandığı girdilere en yüksek ağırlıklar verilerek model kurulmaktadır. Aşağıdaki tabloda CCR-O modeline göre etkin olmayan ülkeler için potansiyel iyileştirilmiş çıtılar, \% değişimler verilmektedir.

Tablo 2. CCR-O modeline göre potansiyel iyileştirmeler

\begin{tabular}{|c|c|c|c|c|c|c|c|}
\hline KVB & SKOR & \multicolumn{3}{|c|}{ GDP } & \multicolumn{3}{c|}{ EMP } \\
\hline & & VERI & PROJEKSIYON & FARK (\%) & VERI & PROJEKSIYON & FARK (\%) \\
\hline MISIR & 0,6006 & 11 & 18,31 & 66 & 8,5 & 19,06 & 124 \\
\hline FRANSA & 0,8567 & 8,9 & 11,20 & 26 & 10 & 11,67 & 17 \\
\hline LÜBNAN & 0,9861 & 18,4 & 18,66 & 1 & 17,9 & 19,32 & 8 \\
\hline KARADAĞ & 0,6769 & 23,7 & 35,01 & 48 & 19,3 & 36,22 & 88 \\
\hline FAS & 0,7647 & 18,6 & 24,32 & 31 & 16,4 & 24,70 & 51 \\
\hline İSPANYA & 0,9484 & 14,9 & 15,71 & 5 & 15,1 & 16,18 & 7 \\
\hline TUNUS & 0,8484 & 14,2 & 16,74 & 18 & 13 & 16,58 & 28 \\
\hline TÜRKIYY & 0,9268 & 11,6 & 12,52 & 8 & 7,4 & 13,06 & 77 \\
\hline
\end{tabular}

Örneğin Türkiye'nin verimli ülkeler arasına girebilmesi için uygulanan çıktı odaklı modele göre, turizm sektörünün GDP içindeki payı \%8 oranında arttırılarak \%12,5 seviyesine aynı şekilde total istihdam içindeki payının da \%77 arttırılarak \%13 seviyesinde olmalıdır.

Bazı ülkelerde (örneğin İspanya'da) turizm sektörünün GSYH içindeki payının nispeten yüksektir. Verimlilik açısından bakıldığında girdilerin yetersiz kullanımı nedeniyle sıralaması düşük olmaktadır.

VZA'nın incelenen pek çok modelinde, etkin olmayan KVB'lerinin etkinlik değerleri 0-1 arasında değerler aldığı için sıralanabilirdir, ancak etkin olan tüm KVB'lerinin etkinlik değerleri "1" olduğu için sıralama mümkün olmamaktadır. Tablo 3'de süper aylak tabanlı model (SBM-O-C) ile hesaplanan sıralama sonuçları verilmekledir.

Uygulanan model görece etkinliği ölçmektedir. Turizm sektörünün etkinliği hesaplanırken tüm ekonomik yönlerinin modelde ele alındığı söylenemez. Aslında bu sektördeki üretim ile çıktı arasındaki oranla ifade edilen üretimin verimliliğine odaklanılmaktadır. Endüstri, belirli bir çıktı 
elde etmek için az miktarda girdi kullandığında veya belirli bir girdi seviyesini kullanarak daha yüksek düzeyde çıtı ürettiğinde daha yüksek verim elde edilmektedir.

Tablo 3. SBM-O-C modeli ile sıralama sonuçları

\begin{tabular}{|c|c|c|c|c|c|}
\hline RANK & ÜLKELER & SKOR & RANK & ÜLKELER & SKOR \\
\hline 1 & KIBRIS & 2,136437 & 12 & LÜBNAN & 0,955494 \\
\hline 2 & CEZAYİR & 1,826802 & 13 & ISPANYA & 0,940099 \\
\hline 3 & LİBYA & 1,584305 & 14 & FRANSA & 0,824593 \\
\hline 4 & \begin{tabular}{|l|} 
ITALYA \\
\end{tabular} & 1,4566 & 15 & TUNUS & 0,809264 \\
\hline 5 & ARNAVUTLUK & 1,364448 & 16 & FAS & 0,710827 \\
\hline 6 & SLOVENYA & 1,279568 & 17 & TÜRKİYE & 0,703218 \\
\hline 7 & BOSNA HERSEK & 1,207129 & 18 & KARADAĞ & 0,596334 \\
\hline 8 & YUNANISTAN & 1,172274 & 19 & MISIR & 0,511892 \\
\hline 9 & HIRVATISTAN & 1,116801 & & & \\
\hline 10 & SURİYE & 1,049692 & & & \\
\hline 11 & İSRAİL & 1,028371 & & & \\
\hline
\end{tabular}

\section{SONUÇ}

Dünya genelinde turizm hareketliliği uluslararası anlaşmazlıklara, siyasi olaylara, terörist faaliyetlere, doğal afetlere, salgınlara, enerji krizlerine ve dünyanın birçok yerinde ekonomik sıkıntıya rağmen yıllar içinde artış göstermiştir. Artan hareketlilik ekonomiler üzerinde doğrudan gelir etkisi yaratırken, aynı zamanda da dolaylı olumlu ekonomik etkiler yaratmaktadır. Dolaylı katkılar ödemeler dengesini iyileştirme, vatandaşların yaşam standartlarını iyileştirme, döviz rezervlerinin biriktirilmesi, mal ve hizmet üretimini artırtılması ve vergiler aracılığıyla devlet gelirlerinin arttırılması sayılabilir. Ayrıca sektör, gelir transferi yoluyla ülkeler arasında sermaye hareketliliği ile ülke gelirleri arasındaki yakınsamaya neden olmaktadır. Bu nedenle, turizm endüstrisinin genişlemesi, dünya genelinde ekonomik kalkınmanın bir motoru olarak görülmektedir. Turizm sektörüne bağlı ekonomik büyüme turizmin ekonomide aktif rolü üzerine kurulmuştur. Sektörün gelişmesi iş hacmini arttırarak, gelirlerin artmasına yol açmaktadır. Ayrıca sektöre yapılan özel/kamu yatırımları, sektörden elde edilen vergi gelirleri, harcamalar ekonomik büyümede çarpan etkisi yaratmaktadır.

Bu çalışmada, sektörün ekonomik etkisi GYSH büyümesi üzerindeki etkisi ve istihdam üzerinde etkisi baz alınarak yapılmıştır. Bu iki çıktı değişkenini doğrudan veya dolaylı olarak etkileyecek girdi değişkenleri seçilmiştir. 2017 verilerinin kullanıldığı modelde, Akdeniz havzasında yer alan 19 turizm destinasyonun teknik (CCR), saf teknik (BCC) ve ölçek etkinlikleri hesaplanmıştır. Seçilen değişkenlere göre tüm ülkelerin ortalama teknik etkinliği \%93 olarak bulunmuştur. Etkinlik değeri 1 olarak hesaplanan ülkeler (Kıbrıs, Cezayir, Libya, İtalya, Arnavutluk, Slovenya, Bosna Hersek, Yunanistan, Hırvatistan, Suriye, İsrail) etkinlik sınırını oluşturmuşlardır. Akdeniz havzasında yer alan turizm destinasyonlarında gözlenen teknik verimsizliğin, hem girdilerin yetersiz kullanılması (yönetimsel verimsizlik) hem de en verimli ölçek büyüklüğünde (ölçek verimsizliği) olmamasından kaynaklanmaktadır. CCR-O modeline göre teknik etkin olmayan ülkeler arasında yer alan Lübnan değişken getiri varsayımına dayanan BCC-O modeline göre saf teknik etkin bulunmuştur. Ölçek etkinliğine göre azalan özellik gösteren Mısır'ın görece ölçek etkin olabilmesi için, uygun ölçek büyüklügüunde faaliyet göstermelidir. İspanya, Fransa, Tunus, Fas, Türkiye, Karadağ dışsal faktörlerden dolayı (coğrafi, iklim, terör, siyasi vb.) kapasitelerinin 
altında çıtı üretmektedir. Bu ülkeler, büyüme potansiyellerini sonuna kadar kullanarak görece etkin hale gelebilirler.

2017 verileri ile yapılan analize göre; 19 ülkenin yalnızca 8'inin görece teknik etkin olmadı̆̆ 1 ve bu ülkelerin, ortalama toplam etkinlik değerinin 0,93 olması göz önüne alınarak, Akdeniz havzasında yer alan turizm destinasyonlarının genel olarak ekonomik etkin olduğu sonucuna varılmıştır. Ancak uygulanan VZA modelleri sadece seçilen değişken ve yıl bazında sonuçlar ürettiği unutulmamalıdır. Ülkeler, ekonomik etkinliğini arttırmak için turizm sektörün GYSH içindeki payını ve istihdam yaratma gücü gibi önemli göstergeleri etkileyecek politikalar uygulamalıdır.

\section{KAYNAKLAR}

Assaf, A. G. and Barros, C. P. (2013). A Global Benchmarking of the Hotel Industry. Tourism Economics, 19(4): 811-821.

Atan, M. ve Arslantürk, Y. (2015). Dünya Ülkelerin Turizm Potansiyelinin Etkinliği. Gazi Journal of Economics and Business, 1(1): 59-76.

Bahar, O. ve Kozak, M. (2005). Türkiye Turizminin Akdeniz Ülkeleri ile Rekabet Gücü Açısından Karşılaştıılması, Anatolia: Turizm Araştırmaları Dergisi, 16(2): 139-152.

Bahar, O. ve Kozak, M. (2013). Turizm Ekonomisi, Editör Metin Kozak, Anadolu Üniversite Yayını No: 2908, Açıköğretim Fakültesi Yayını No: 1865, 1. Baskı, Eskişehir

Banker, R.D. and Morey, R.C. (1986). Efficiency Analysis for Exogenously Fixed Inputs and Outputs. Operations Research, 34(4): 513-521.

Barros, C. P. and Mascarenhas, M. J. (2005). Technical and Allocative Efficiency in a Chain of Small Hotels. International Journal of Hospitality Management, 24(3): 415-436.

Charnes, A.C. and Cooper W. W. (1985). Preface to Topics in Data Envelopment Analysis. Annals of Operations Research, 2 (1): 59-94.

Charnes, A.C., Cooper, W.W. and Rhodes E. (1978). Measuring the Efficiency of Decision-Making Units. European Journal of Operational Research, 2(6): 429-444.

Cracolici, M. F., Hijkamp, P., and Rietveld, P. (2008). Assessment of Tourist Competitiveness by Analysing Destination Efficiency, Tourism Economic, 14(2): 325-342

Çelik. K. A., Özcan. S., Topçuoğlu. A. and Yıldırım, E. K. (2013). Effects of The Tourism Industry on The Balance of Payments Deficit. Anatolia. An International Journal of Tourism and Hospitality Research, 24(1): 86-90.

Çımat, A. ve Bahar, O. (2003). Turizm Sektörünün Türkiye Ekonomisi İçindeki Yeri ve Önemi Üzerine Bir Değerlendirme, Akdeniz İ.I.B.F. Dergisi, (6): 1-18

Fare, R., Kirkley, J. E. and Walden, J. B. (2007). Estimating Capacity and Efficiency in Fisheries with Undesirable Outputs. VIMS Marine Resource Report No. 6.

Fuchs, M. (2004). Strategy Development in Tourism Destinations: a DEA approach. Poznan University Economic Review, 4(1): 52-73

Göral, R. (2018). ESM-VT Yöntemi ile Uluslararası Destinasyonların Turizm Sektörü Etkinliğinin Değerlendirilmesi, Journal of Tourism and Gastronomy Studies, 6(2): 436-455 
Göral, R. ve Tengilimoğlu, E. (2018). Türk Dünyası Destinasyonlarının Turizm Sektörü Etkinliğinin Karşılaştırması, Uluslararası Türk Dünyası Turizm Araştırmaları Dergisi, 3(2): 230-241

Gürsoy, Y. ve Göral, R. (2019). Comparison of Tourism Sector Efficiencies of International Destinations with Super Efficiency Method, International Journal of Scientific and Research Publications, 9(2): 164-169

Hadad, S., Hadad, Y., Malul, M. and Rosenboim, M. (2012). The Economic Efficiency of The Tourism Industry: A Global Comparison. Tourism Economics, 18(5): 931-940.

Kosmaczewska, J. (2014). Tourism Interest and the Efficiency of Its Utilisation Based on the Example of the EU Countries. Acta Scientiarum Polonorum Economia, 13(1): 77-90.

Kozak, M., and Rimmington, M. (1999). Measuring Tourist Destination Competitiveness: Conceptual Considerations and Empirical Findings, International Journal of Hospitality Management, 18: 273-283.

Kozak, M. (2004). Measuring Comparative Performance of Vacation Destinations, içinde G. I. Crouch vd., (Ed.), Consumer Psychology of Tourism, Hospitality and Leisure. Wallingford: CAB International

Lorcu, F. (2008). Veri Zarflama Analizi (DEA) ile Türkiye ve Avrupa Birliği Ülkelerinin Sağllk Alanındaki Etkinliklerinin Değerlendirilmesi. İstanbul Üniversitesi Sosyal Bilimler Enstitüsü. (Yayımlanmış Doktora Tezi). İstanbul

Page, J. S. and Cornell, J. (2014). Tourism a Modern Synthesis, Singapore, 4th Edition, Singapore: Cengage Learning

Patsouratis, V., Frangouli Z. and Anastasopoulos G. (2005). Competition in Tourism among the Mediterranean Countries, Applied Economics, 37(16): 1865-1870

Pestana, B. C., Botti, L., Peypoch, N., Robinot, E., Solonandrasana, B., and Assaf, A. G. (2011). Performance of French Destinations: Tourism Attraction Perspectives. Tourism Management, 141146

Sathye M. (2001). X-Efficiency in Australian Banking: An Empirical Investigation. Banking and Finance 25(3): 613-630

Soysal -Kurt, H. (2017). Measuring Tourism Efficiency of European Countries by Using Data Envelopment Analysis. European Scientific Journal, 13(10): 31-49.

Thano, R. (2015). The Impact of Tourism on the Balance of Payments. American Journal of Economics, Finance and Management, 1(5): 529-536

Türkcan, B. (2018). Türkiye'de İç Turizm Harcamaları ile Ekonomik Büyüme İlişkisi. Efil Journal, 1(1): 158-171

Usta, Ö. (2009). Turizm, Genel ve Yapısal Yaklaşım, Detay Yayıncılık, Ankara

Ünlüönen, K. ve Şahin, S. Z. (2011). Turizmde İstihdam, Elektronik Sosyal Bilimler Dergisi, (10/37): $1-25$

Yükçü S. ve Atağan, G. (2009). Etkinlik, Etkililik ve Verimlilik Kavramlarının Yarattığı Karışıklık. Atatürk Üniversitesi İktisadi ve İdari Bilimler Dergisi, 23(4): 1-13

World Travel and Tourism Council. (2018). Travel and Tourism Economic Impact 2018: World. London: WTTC, [Erişim tarihi: 15.05.2019] 
World Tourism Organization, (Dünya Turizm Örgütü) (UNWTO)Tourism Highlights 2018 Edition, https:// www.e-unwto.org/doi/pdf/10.18111/9789284419876 [Erişim tarihi: 03.05.2019]

World Travel and Tourism Council (Dünya Turizm ve Seyahat Konseyi) 2018 (WTTC 2018), https://www.wttc.org/-/media/files/...2018/world2018.pdf [Erişim tarihi: 21.05.2019]

Zaei. E. M. and Zaei. E. M. (2013). The Impacts of Tourism Industry on Host Community. European Journal of Tourism Hospitality and Research, 1(2): 12-21, 